\title{
O objeto editorial contemporâneo: transdisciplinaridade, cultura e consumo nas publicações independentes.
}

The contemporary editorial object: transdisciplinary, culture and consumption in independent publishing.

Jorge Otávio Zugliani \& Mônica Cristina de Moura.

Design Contemporâneo, Design Editorial, Publicação Independente, Autoria, Transdisciplinaridade

As publicações independentes apresentadas em feiras especializadas têm despertado o interesse do público e pesquisadores de diversas áreas de conhecimento. Tais obras envolvem diálogo interdisciplinar e transdisciplinar. A composição material, estrutural, gráfica, imagética e as narrativas textuais, adotam concepções experimentais que discutem temas atuais e exploram os aspectos de autoria e do leitor/interator. Os referenciais teóricos abrangem desde a filosofia e sociologia, cultura e consumo, passando por conceituações artística e aportando nas teorias específicas do design, no intuito de apresentar tais objetos editoriais contemporâneos como portadores de sentido e tradutores deste tempo.

\section{Contemporary Design; Editorial Design; Independent Publishing; Authorship; Transdisciplinarity}

Independent publishing presented today at specialized fairs have attracted interest from the public and researchers from various fields of knowledge. These works involve interdisciplinary and transdisciplinary dialogue. The material, structural, graphic, and imaginary composition and textual narratives adopt experimental conceptions that discuss current themes and explore the aspects of authorship and the reader/interactor. The theoretical references range from philosophy and sociology, culture and consumption, passing through artistic conceptualizations and considering the specific theories of design, in order to present such contemporary editorial objects as meaning bearers and translators of this time.

\section{Introdução}

As publicações independentes tem sido o foco de investigação no Grupo de Pesquisa em Design Contemporâneo: sistemas, objetos e cultura, vinculado ao Programa de Pós-graduação em Design, Unesp, Bauru. Tais obras protagonizam um novo cenário de criação de livros e se colocam na contramão do mercado editorial tradicional, possibilitando uma série de análises.

As feiras de publicações independentes se fortalecem, tanto como local de divulgação e comercialização, quanto ponto de encontro entre os agentes que articulam o cenário. O objeto editorial contemporâneo envolve em suas questões conceituais o diálogo interdisciplinar entre design gráfico, editorial e contemporâneo, e o diálogo transdisciplinar entre design, arte e literatura. Apresenta uma configuração que adota concepções experimentais que refletem e discutem a contemporaneidade, explorando os aspectos de autoria tanto do autor quanto do interator ${ }^{1}$.

Assim, qual a linguagem informacional dominante? Quais as características sintáticas, semânticas e simbólicas esses objetos e produtos culturais trazem à tona? Como e porque eles se inserem na contemporaneidade? Quais as relações com outras áreas de conhecimento?

Por meio de uma pesquisa bibliográfica e documental, apontamos fundamentos do design, da arte, da filosofia e sociologia para estabelecer parâmetros de análise com dados recentes

${ }^{1}$ Nomenclatura cunhada por Janet Murray ao tratar do receptor nas narrativas hipermidiáticas. Machado, A (2001), 0 sujeito no ciberespaço, INTERCOM, adota a mesma nomenclatura. Mônica Moura inclui em seus textos a designação interator para o leitor e usuário tanto nas propostas hipermidiáticas, quanto na relação sujeito e objeto resultante do design contemporâneo.

Anais do 9 $\mathrm{CIDI}$ e 9 CONGIC

Luciane Maria Fadel, Carla Spinillo, Anderson Horta,

Cristina Portugal (orgs.)

Sociedade Brasileira de Design da Informação - SBDI

Belo Horizonte | Brasil | 2019

ISBN 978-85-212-1728-2
Proceedings of the 9th CIDI and 9th CONGIC

Luciane Maria Fadel, Carla Spinillo, Anderson Horta, Cristina Portugal (orgs.)

Sociedade Brasileira de Design da Informação - SBDI Belo Horizonte | Brazil | 2019

ISBN 978-85-212-1728-2 
obtidos dos próprios agentes e outros artigos. Os exemplos coletados para a observação advêm do período e cenário de publicações independentes mencionados e presentes nas principais feiras contemporâneas desse segmento.

\section{Metodologia}

O método adotado é qualitativo, contemplando as seguintes modalidades de pesquisa: bibliográfica, de acordo com a teoria em design, arte, filosofia e sociologia, permitindo estudar questões de autoria, cultura e consumo na contemporaneidade; documental, com coleta de dados do universo do objeto de estudo, como números de feiras, público e expositores; mapeamentos de tais dados; pesquisa de campo, além de estudos de casos com análises sintáticas-estético formais e semântico-simbólicas de 3 casos distintos. A pesquisa bibliográfica é assistemática e exploratória com base em material já publicado.

\section{Objeto Editorial Contemporâneo}

Ao trabalhar o conceito de objeto, Abraham Moles (1981) atribui a ideia de produto específico criado pelo homem, de forma que ele possa segurar e/ou manipular. Há também uma questão imaterial nesta criação quando se refere à cultura como um produto da ação humana.

Se o campo de ação do design é o da configuração de objetos (Bomfim, 1997) e sabe-se que o design tem um caráter intencional ao intervir no objeto e na relação entre o homem e o meio (Krippendorff, 2001), entendemos que o designer é um produtor de cultura em sua ação projetual, pois os objetos projetados se transformam em bens, gerando desejos, modificando e revalorizando situações ou ambientes.

O design, hoje, se mostra de modo integrado, negando a divisão indústria/produtos e visual/gráfico, assim como supera também as distinções limitadoras entre arte e artesanato. Deste modo, vemos o objeto livro a partir das linguagens e das poéticas visuais que geram quando em contato com o interator, mesmo quando apresenta preocupações mercadológicas.

A arte usa a nomenclatura 'livro de artista' que, normalmente, se refere a exemplares únicos. Silveira (2008) relaciona que: o livro de artista pode designar tanto a obra como a categoria artística; o conceito é problemático e envolve outras áreas de conhecimento; a concepção e execução do livro de artista pode ser apenas parcialmente executada pelo artista ou envolver terceiros; o produto resultante não precisa necessariamente ser livro, bastando estar relacionado; e seus limites envolvem questões do afeto. $O$ autor considera a coletividade, a transdisciplinaridade, a pluralidade estética e simbólica do objeto, assim como a afetividade.

Paiva (2010), reforça que o livro é artesanal por vocação e aplica a tecnologia a serviço da inventividade. A escolha do suporte de leitura, acabamentos e efeitos especiais, engenharia do papel, colagens, montagens, costuras, mesclas de pintura, escultura, desenho, fotografia, serigrafia, resgatam componentes estéticos puros, como formas, linhas, cores, volumes.

Estas definições apontam que tais similaridades são exemplos da complementariedade entre a arte e o design contemporâneo. Os objetos de design se aproximam da arte ao trazerem discussões contemporâneas sobre questões sociais, políticas e ao refletir e questionar a vida (Moura, 2010). Assim, propõem-se o termo 'Objeto Editorial Contemporâneo' em lugar do termo 'livro de artista'. Amplia-se o conceito sem desviar do objetivo: entender as configurações e relações destes objetos. Possibilitando inferir que, assim como as publicações independentes, o livro de artista reside dentro do arco do objeto editorial contemporâneo.

Sobre este tempo compreendido como contemporâneo, Agambem (2009) define que ser contemporâneo é ter um entendimento e visão lúcida de seu próprio tempo, e para isso, é preciso haver um distanciamento. Aqueles que coincidem plenamente com sua época e estão perfeitamente adaptados, não seriam considerados contemporâneos, exatamente por não verem e não refletirem, não estabelecendo um pensamento crítico. 
O design se faz importante ferramenta de análise a este respeito, não apenas por ser uma área criadora, mas por ter natureza essencialmente especular, investigativa, seja como anúncio, seja como denúncia (Bomfim, 1997).

No início do design no Brasil, tal característica transdisciplinar era atribuída apenas à arte. Conduta que gerou uma sequência de definições formais que por muito tempo impregnaram o design brasileiro, tornando-o inflexível. O design brasileiro contemporâneo tem atuado mais intensamente na esfera conceitual e subjetiva, tornando os designers profissionais tradutores de sentido e da fluidez do tempo. (Moura, 2015).

Sabe-se que, tanto a ideia de auto publicação como a prática do livro de artista, não são fenômenos atuais. Um exemplo pertinente é o grupo O Gráfico Amador. Surgido em Pernambuco, em 1954, o coletivo propunha editar textos literários recusados pelos grandes circuitos. A extensão técnica e estética das obras não deveria ultrapassar as limitações de uma oficina de amadores (Lima, 2014). Foi um coletivo editorial transdisciplinar, com tiragens modestas e uma visão projetual que utilizou as adversidades financeiras e geográficas para potencializar as poéticas geradas na materialidade de seus produtos. Graças às investigações estéticas e aprimoramento intelectual de Aloísio Magalhães, os experimentalismos do coletivo interferiram na narrativa, na autoria e na relação com o leitor interator.

\section{Publicações e feiras independentes}

De acordo com Muniz (2010), publicar, tornar público, é uma ação política, é um ato de assumir posição no campo das ideologias. O autor observa que nas últimas décadas, produtores simbólicos têm surgido e se qualificado como independentes. Este adjetivo passou a frequentar o debate sobre arte e cultura, definindo grupos e produtos em diversas áreas.

Em termos gerais a produção cultural independente será concebida como aquela que está fora - ora por escolha, ora por condição - dos circuitos e mercados massivos; que não adotam as lógicas dos grandes conglomerados de cultura e mídia; que se identifica com os métodos artesanais de produção, com o experimentalismo estético e/ou com discursividades dissonantes, alternativas, contrahegemônicas. Ao mesmo tempo que se opõe implicitamente ao dependente (...), esse produto se definirá a contrapelo de certos carrascos da dependência - o mercado, o mainstream, as empresas privadas, os grandes conglomerados, as instâncias públicas etc. que controlam a produção, a circulação e a consagração dos bens simbólicos (Muniz, 2016, p.16)

A maioria dos que atuam nesse cenário, sejam indivíduos ou grupos de pequeno porte, operam informalmente. Alguns chegam a se formalizar como pequenas empresas, contudo, nos interessa destacar que este fator formal/informal não determina a qualidade do que se apresenta, a seriedade como se oferece, tampouco o "grau" de independência desses autores e editores.

Nos últimos anos surgiram locais realmente diferenciados, que buscam cada vez mais oferecer publicações de uma maneira que a livraria tradicional não poderia oferecer, assim como apresentar obras com estruturas ou conceitos que se afastam do modelo convencional. No ano de 2007, surgiu a Banca Tijuana, situada na Galeria Vermelho, em São Paulo. ${ }^{2}$ Em suas fases iniciais, da banca e da Feira Tijuana, de 2010, são marcadas pelo livro de artista como exemplar único.

Por outro lado, a Feira Plana ${ }^{3}$, de 2013, parece ser, de fato, a eclosão de um cenário editorial que busca profissionalização e sequencialidade nos títulos, estimulando outros eventos e objetos que vislumbram planejamento e tiragem maior que o exemplar único, considerando o design na composição e no uso das tecnologias de impressão e acabamento, maior organização dos coletivos ou pequenas editoras, além de maior elaboração de conteúdo editorial nas publicações.

\footnotetext{
2 Tijuana, Feira. Site oficial do evento. https://cargocollective.com/tijuana/. Recuperado em 17 mai. 2019.

3 Plana, Feira. Homepage oficial do evento. http://www.feiraplana.org/. Recuperado em 17 mai. 2019
} 
Somente em 2018, foram divulgados 110 eventos nacionais com feiras dedicadas especificamente à arte impressa e à publicação independente. Tal número foi obtido pela lista online $^{4}$ disponibilizada e atualizada pelos principais realizadores de eventos do país (Gráfico 1 ). Estes dados, somados às informações citadas pela organizadora da Plana, Bia Bittencout ${ }^{5}$, e complementados pelos dados apresentados por Muniz (2017), além de outras informações coletadas em jornais impressos e sites que relataram os eventos ${ }^{6}$, possibilitam o mapeamento deste setor (Gráfico 2).

Gráfico 1: Feiras independentes/ano.

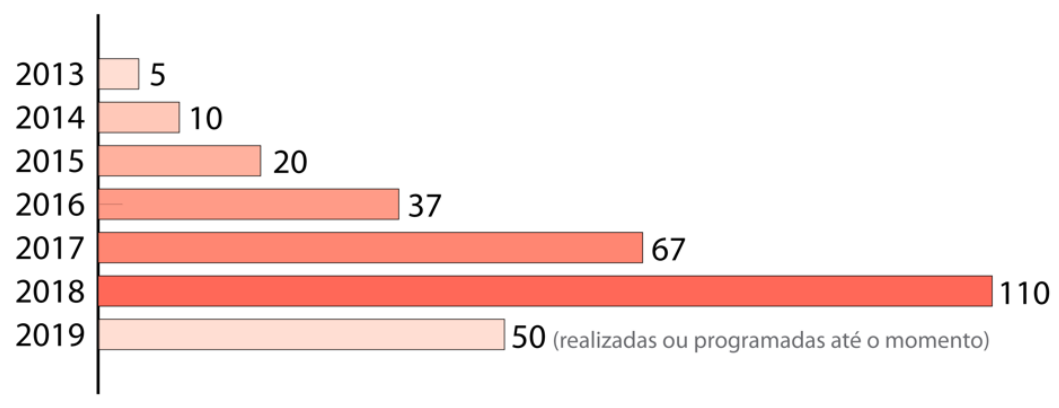

Gráfico 2: Feiras de publicação independente no Brasil, em 2018.

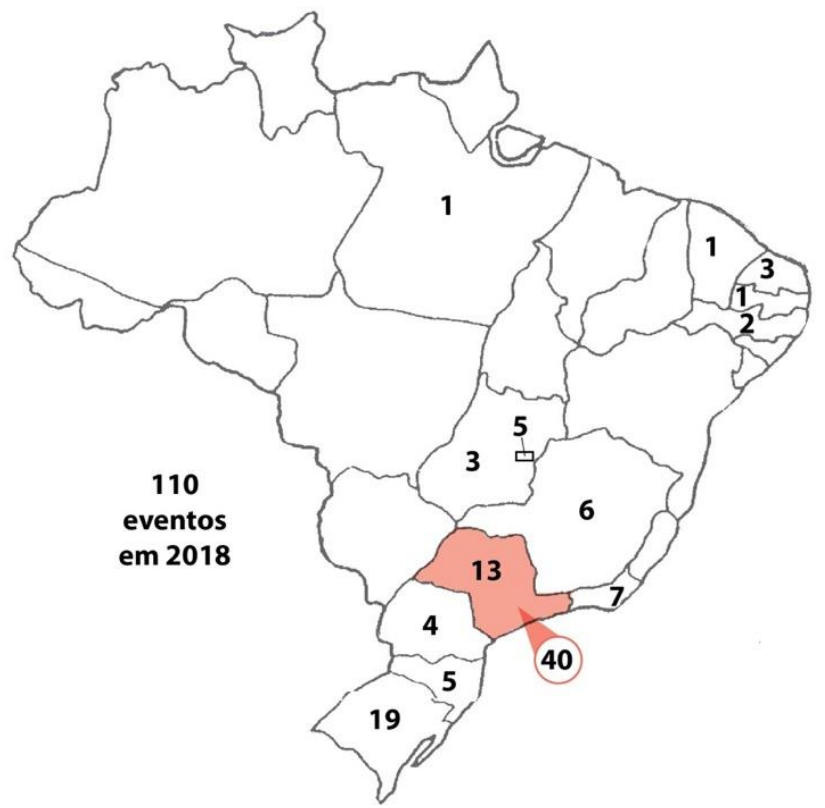

O impacto causado pela edição de 2017 da Feira Plana (Gráfico 3), pode sugerir o grande sucesso do evento e do interesse do público nestes tipos de publicações ou uma consolidação da qualidade destes objetos. Nota-se, por exemplo, o salto quantitativo de eventos que ocorreram em 2018 (Gráfico 1), provavelmente impulsionados pelo sucesso da edição de 2017 da Plana.

${ }^{4}$ Lista pública de feiras: https://goo.gl/hN2ymK, recuperado em 17, mai. 2019

${ }^{5}$ Meca Journal \#18: http://meca.love/midia-mecajournal-018/ e http://revista.usereserva.com/2017/12/20/feira-plana-biabittencourt/, recuperado em 17, mai. 2019.

${ }^{6}$ FFW: https://tinyurl.com/y4oq8nfd e Fala! Universidades: https://tinyurl.com/y4uyd5bh e Cafeína Zine: https://tinyurl.com/y4auw43u, recuperados em 17, mai. 2019. 
Gráfico 3: Feira Plana: relação entre a quantidade de expositores e visitantes por edição.

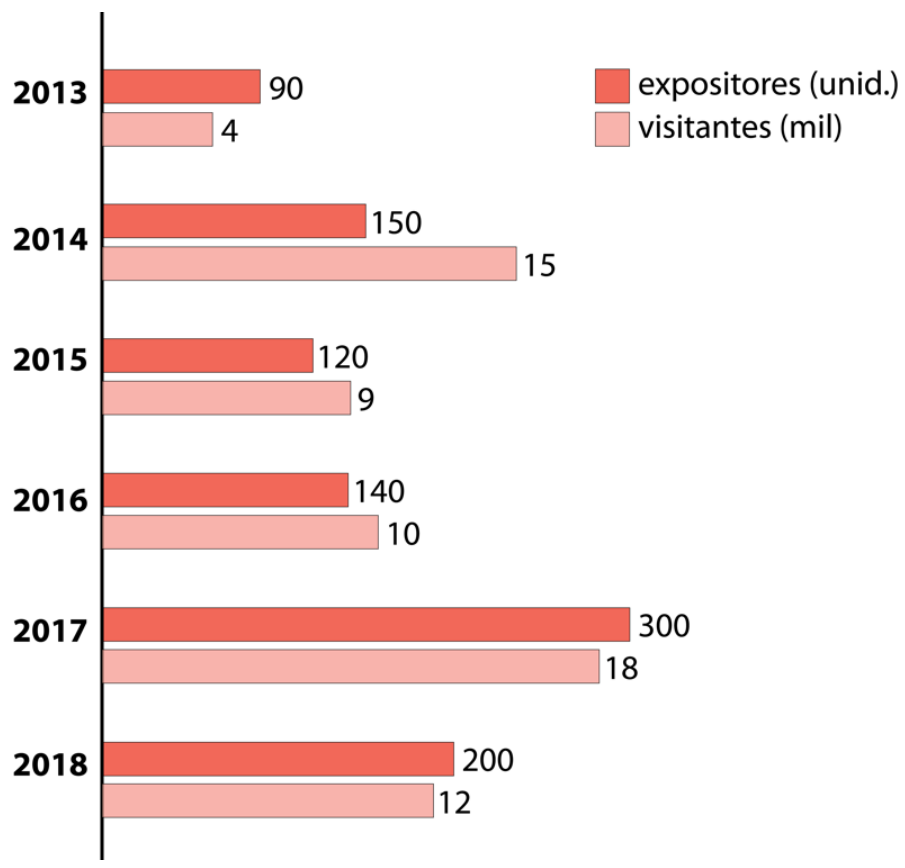

De acordo com o documentário Impressão Minha ${ }^{7}$ e o jornalista Ronaldo Bressane, no MECA Journal \#18 ${ }^{8}$, apesar de ser um fenômeno nacional, as cinco feiras regulares mais representativas atualmente, estão na cidade de São Paulo: Plana Festival; Feira Tijuana; UgraZineFest/Des.gráfica; Feira Miolo(s); e Printa Feira. Outros nomes importantes que surgem no país são: Parada Gráfica (RS), Feira Grampo (PR), e Feira Dente (DF).

\section{Cultura e consumo do objeto editorial contemporâneo}

Com a revalorização do produto na hipermodernidade, a mercadoria elaborada adquiriu também um valor simbólico, com ênfase tanto materialista, quanto cultural. Featherstone (1995) diz que os bens, além do tradicional, apontam para outras questões, como os modos de uso que demarcam relações sociais. Lipovetsky e Serroy (2015) comentam que hoje a cidade se afirma como um local de atração, compras e cultura, formando um espaço transestético, gerando uma atmosfera de sensações e busca por prazeres.

Paralelo à inegável qualidade do que é oferecido, a cena independente estaria em evidência também por conta dos espaços lúdicos que ela cria?

Lipovetsky e Serroy (2015) explicam que o consumo estético é fruto do capitalismo artista. Quando as camadas populares progridem do consumo essencial para o exagero, surge 0 consumo estetizado. O mercado absorve a arte, assim como outras áreas, para articular a produção de bens e serviços, com a finalidade de monetizar não apenas os produtos, mas a própria estética e as emoções.

Featherstone (1995) comenta que a elite cultural, pela manutenção de suas habilidades, promove atividades sobre como usar e consumir com adequação em qualquer situação, 'o consumo de bens da alta-cultura (arte, romances, ópera, filosofia) precisa estar associado aos modos de manusear e consumir outros bens culturais mais mundanos' (Featherstone, 1995, p. 37).

\footnotetext{
7 Documentário Impressão minha. (2018) Salaroli, D,; Leite, G.; \& Rabello, J. V. São Paulo: Peripécia Filmes.

${ }^{8}$ Bressane, Ronaldo. (2018) Multiplicar e dividir. Em Meca Journal, São Paulo, n.18, (pp.10-13).
} 
Supomos que em nosso objeto de estudo, além da tradicional lógica de mercado, demanda/produção; do interesse contemporâneo em consumo estético; e da presença do design atuando de maneira distinta à sua origem; há também o oferecimento de serviços e experiências. Ações paralelas que evidenciam não se tratar apenas de mercado, mas de práxis culturais, fazeres conectados à reflexão. Tais experiências têm formatos de debates a respeito das publicações, palestras, oficinas, encontros e capacitações, que possivelmente estimulam o movimento a crescer e se diversificar, configurando-se como atividades que visam ensinar como usar e consumir tais produtos, bem como demonstrar as habilidades dos criadores entre os seus pares.

\section{Características do Objeto Editorial no Design Contemporâneo}

\section{Coautoria entre autor e leitor e a narrativa}

Barthes (2004) explica que o lugar onde a multiplicidade de ideias se reúne é no leitor e não no autor. O que importa quem fala, se o que se fala é uma colcha de retalhos de diversos discursos para se fechar um conceito? Agamben (2009) explana que a fala do autor se confunde com a de seu intérprete e o leitor do texto/legado abandona o que está analisando para seguir por conta própria, expandindo suas ideias de acordo as exigências políticas e morais de seu próprio tempo.

Esta troca de papéis e poder, entre o autor e o leitor está presente na contemporaneidade, como também, a auxilia em sua definição. Consideramos o leitor-usuário do objeto editorial e sua importância enquanto coautor, pois, é na sua prática (experiência/aprendizado) que a obra se conclui e se torna única, gerando, por sua vez, um novo discurso.

De acordo com Benjamin (1994), narrar seria justamente a faculdade de intercambiar experiências. Durante este desenvolvimento da autoria pelo tempo, a valorização simbólica da composição física do texto caminha junto, e consequentemente, influencia a narrativa de seu conteúdo expresso. Neste sentido, sugere-se o autor como produtor, organizador do discurso em todos os seus aspectos, sem desconsiderar o leitor na formação da narrativa.

\section{Design Gráfico Editorial}

Embora sua origem tenha acompanhado as ideias funcionalistas características do início da formação do design, o design gráfico editorial, sempre primou pela clareza e organização modernista dos conteúdos. Apesar desta estrutura ser útil no sistema de produção, deve-se considerar que a pós-modernidade trouxe questionamentos para os designers, entre eles, a associação do papel do editor e do designer. O designer como editor torna-se responsável por todo o processo que envolve o design editorial, desde a seleção dos conteúdos à construção da proposta visual e verbal existente no produto editorial. (Poynor, 2010).

O produto editorial também se desvinculou da necessidade da grande produção fortalecendo pequenas tiragens e a produção da peça única, desenvolvidas para nichos, sendo denominada publicação independente. Neste contexto, a ação projetual do design editorial contemporâneo constrói discursos pautados no aprofundamento dos conteúdos e na relação entre a pesquisa teórica e crítica para o desenvolvimento da área gráfica.

O design editorial "age como um instantâneo cultural vivo da época em que é produzido" (Caldwell \& Zapaterra, 2014, p.10). Envolve a curadoria de narrativas, o compartilhamento de pontos de vista e interesses, não está mais vinculado apenas a mancha gráfica, estendem-se das mídias impressas tradicionais até os dispositivos digitais e pode entreter, informar, instruir, comunicar, educar ou combinar todas essas atividades.

O conceito de autoria está enraizado na criação independente de ideias. Contudo, escolhas pessoais não the dariam o título de autor total ao designer experimental na confecção de livros. Sua conexão com o conteúdo precisa ser mais profunda. Lupton e Miller (2008) indicam que design, escrita e pesquisa são questões indissociáveis. 
Poynor salienta que a inventividade em design de livros reforça o design gráfico como uma prática de pesquisa de vanguarda na literatura visual, esclarecendo que é possível atuar com sucesso neste campo com os subsídios que o design dispõe, e talvez, com mais desenvoltura no diálogo transdisciplinar, justamente porque assimilar conteúdos é uma característica intrínseca ao design. Desta forma, o pesquisador revisa os autores mencionados e sugere nomenclaturas que relativizam a expressão "designer como autor", propondo, "designer como produtor", "designer como diretor", ou "designer como tradutor" (Poynor, 2010, p. 146).

\section{Funções do design}

A relação forma e conteúdo transparece as preocupações sociais de cada época. Houve períodos em que a função do objeto era o que importava em detrimento da forma; em outros momentos históricos, a forma tinha privilégio, prejudicando em alguns casos a função. $\mathrm{Da}$ mesma maneira, há uma época, possivelmente a contemporânea, em que as questões simbólicas (emoção, afeto, memória, status etc.) proporcionadas por um objeto são mais relevantes que sua função original.

Estes elementos estão extremamente conectados e, deste modo, recorreremos aos aportes teóricos da disciplina para entender as configurações dos produtos de design. Burdek (2010) observa que as funções perceptivas intermediam os sentimentos das pessoas, levando sempre em consideração o contexto social, tecnológico ou cultural em que o produto foi projetado, discorrendo, assim, sobre as funções estético-formais, as funções indicativas e as funções simbólicas. Lobach (2001), por sua vez, ao comentar que uma rocha, para o homem, pode não ter nenhuma função prática. Porém, ao observarmos seu formato (função estética) ela pode nos remeter à imagem de um animal (função simbólica), evidencia as funções dos produtos industriais, em uma analogia que lembra as colocações de Moles (1981).

Escorel (2000) propõe outra maneira de pensar estes conceitos, ao explicar que a linguagem do design pode ser entendida com duas principais possibilidades de articulação: as propriedades combinatórias (aspectos formais) e as propriedades associativas (aspectos simbólicos). O produto e seu significado resultam da soma destes dois fatores e das interferências de caracteres contextual e pessoal.

\section{Resultados}

A partir destas reflexões sobre design editorial, autoria, transdisciplinaridade e outras questões contemporâneas, elegemos três exemplos de livros para analisar, dentro do cenário apresentado e no recorte de tempo estabelecido. Nossa intenção é localizar nestes produtos características do objeto editorial contemporâneo.

\section{Gustavo Piqueira. Obra: Oito Viagens ao Brasil}

Gustavo Piqueira, além do trabalho consolidado com a Casa Rex, nunca deixou de lado as experimentações editoriais, organizando equipe e espaço para viabilização de projetos independentes que utilizam técnicas artesanais e exploram as narrativas verbais e visuais. Dá atenção aos elementos táteis que dialogam com o texto verbal, influenciando a leitura da história e construindo um novo enredo. Seu trabalho evidencia o debate sobre o designer autor/produtor.

Em Oito Viagens ao Brasil, 2017, cria personagens que narram a história, gerando um humor que potencializa a experiência de leitura, fazendo com que o conteúdo, que poderia ser cansativo (um texto corrido ao redor da narrativa original do alemão Hans Staden), se torne prazeroso e divertido, facilitando a aquisição de conhecimento. Destaca-se que o texto é elaborado e desenvolvido por Piqueira, que assume o papel de coletor de dados históricos, escritor e designer. Um editor que, tal qual um diretor de teatro, organiza os personagens e seus discursos. 
Zugliani, J. O. \& Moura, M. C. de | Objeto editorial contemporâneo: transdisciplinaridade, cultura e consumo nas publicações independentes.

Figura 1: Oito viagens ao Brasil. Caixa e capas. Acervo do autor.

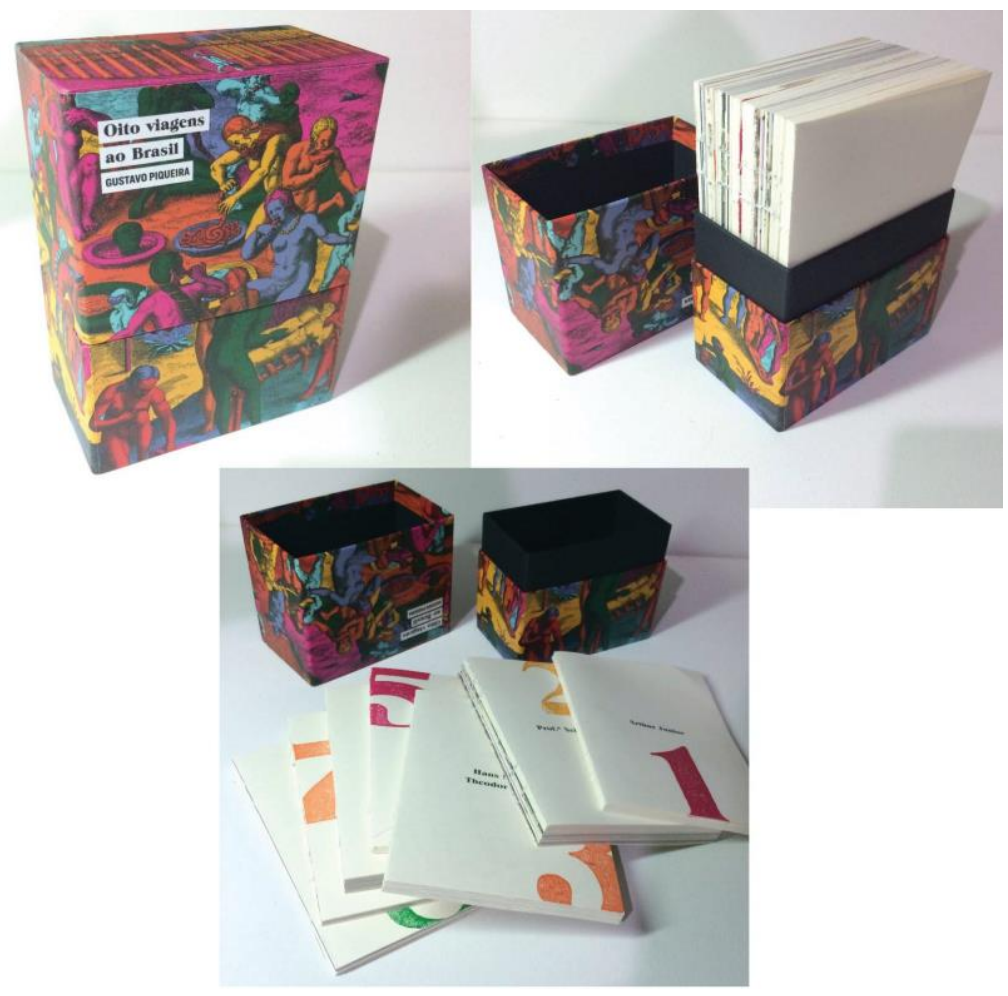

Figura 2: Lombada e páginas. Acervo do autor.

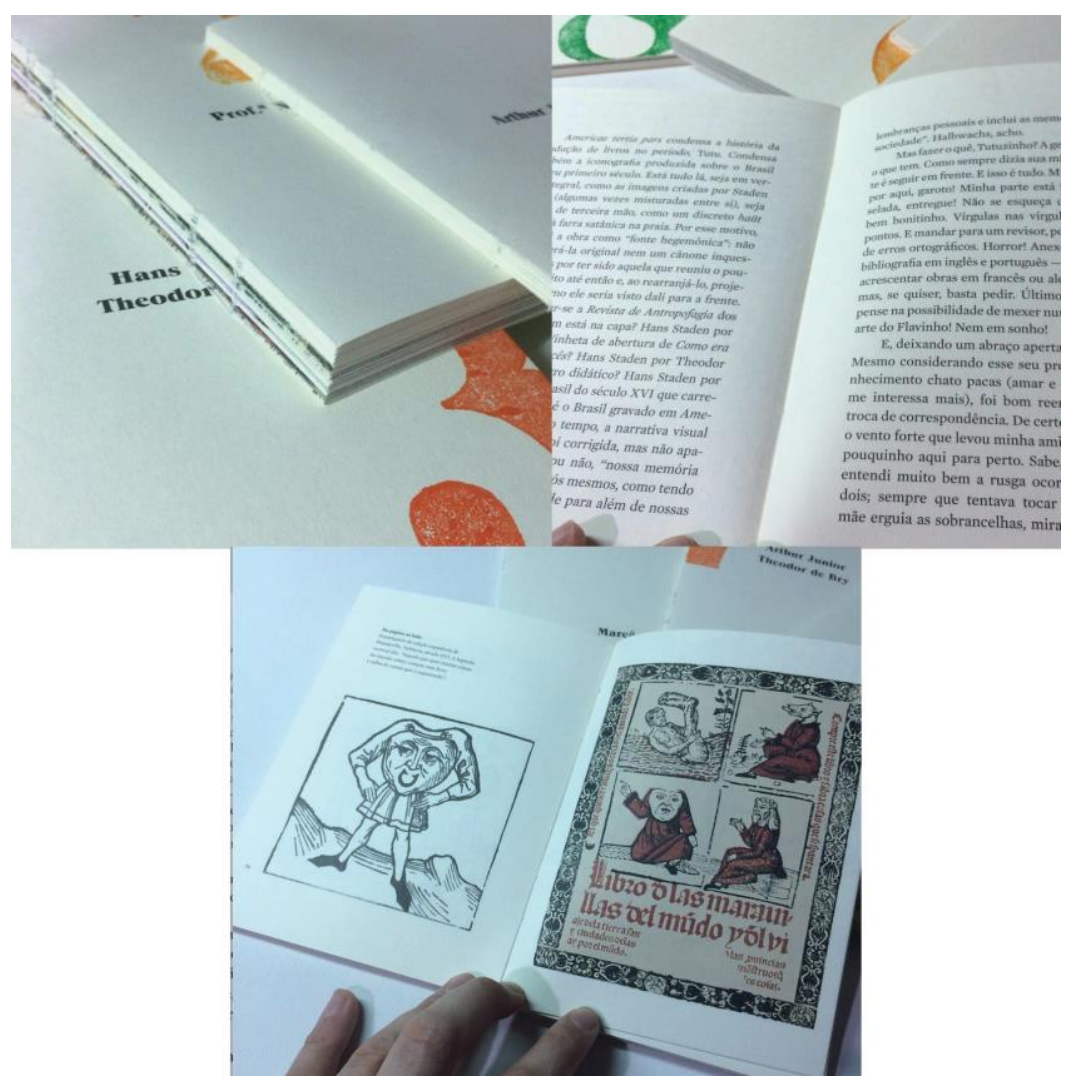

Anais do 9o Congresso Internacional de Design da Informação | CIDI 2019 
A caixa de papelão é revestida, com imagens retiradas das obras de Staden e coloridas de forma simples, remetendo às antigas limitações técnicas de impressões. Dentro da caixa, encontram-se oito cadernos cujos miolos foram impressos em offset, mas com as costuras à mostra, sem acabamento. Os números foram impressos nas respectivas capas, utilizando tinta tipográfica e matrizes de MDF entalhadas na oficina da Casa Rex. 1000 exemplares.

Ao escrever o texto, Piqueira ironiza a questão da autoria. Cada volume encontrado dentro da caixa é assinado por um personagem fictício diferente: uma professora, um amigo, um recém-formado. Cada um tem uma abordagem diferente na configuração textual, uma voz, um tom, e foram escolhidos e organizados por outro personagem fictício, o inseguro editor Arthur. Ao abrir a caixa e folhear os volumes, nota-se que um deles está rasgado. Na leitura, entendemos que o protagonista Arthur já planejava rasgar as páginas enquanto editava, por razões pessoais.

O designer Piqueira se apropria do texto na sua criação e manipulação do seu conteúdo, não apenas na sua diagramação e aspectos formais. Associada a todos os elementos estruturais, o designer informa algo ao público. Mescla a memória do conteúdo histórico com a memória afetiva dos personagens, e consequentemente, do leitor, gerando uma interação inesperada. A maneira como o leitor compreende, se envolve e aprende o conteúdo desta obra se compara a maneira como a informação nos é oferecida na contemporaneidade, fragmentada, com fontes dispersas e repleta de digressões.

\section{Coletivo Charivari. Obra: Charivari \#2.}

O Coletivo Charivari é formado por profissionais de diversas áreas, como design, arte, ilustração e literatura, que atuam, desde 2005, produzem e vendem suas publicações que priorizam técnicas manuais de impressão e encadernação.

A palavra "Charivari" que na linguagem circense refere-se ao momento em que todos os artistas do circo se apresentam mostrando o que fazem de melhor. Caracteriza o trabalho do coletivo, onde os experimentos gráficos individuais geram novas poéticas no cruzamento dos trabalhos de cada membro.

Cada edição explora um formato diferente, resultado da experimentação coletiva, sempre em baixas tiragens custeada pelo próprio grupo, e, em alguns casos, com apoios de instituições culturais. A edição número 2, 2008, 500 exemplares, apresenta capa de papelão, com frisos regulares na vertical e um "Ch" vazado em traçado orgânico. As páginas internas são impressas em serigrafia, preto e branco, utilizando as cores dos papéis, permitindo uma várias combinações e texturas. Trata-se de um caos gráfico que se alinha quando percebemos que todas as ilustrações remetem ao caos urbano.

$\mathrm{Na}$ ocasião dos lançamentos e eventos, organizam exposições e oferecem oficinas práticas nas quais o público pode experimentar a linguagem. Além do planejamento envolvendo o aproveitamento de materiais e baixa-tiragem, consideramos que design gráfico tem uma preocupação social ao intervir na sociedade proporcionando reflexão de classe, tanto no que diz respeito ao acesso fácil à uma mídia, como em dar voz a quem não tinha.

A atuação destes profissionais na área editorial independente vai além da mera experimentação autoral. Por meio das práticas de oficinas e intervenções, capacitam outras pessoas. Isto vai de encontro com a práxis cultural citada, um fazer conectado à reflexão. Atividades paralelas ao consumo material que visam ensinar como usar e consumir com adequação tais produtos, bem como demonstrar as próprias habilidades dos criadores entre os seus, inscrito no mesmo espaço social cultural. 
Figura 3: Charivari 2. Acervo do autor.
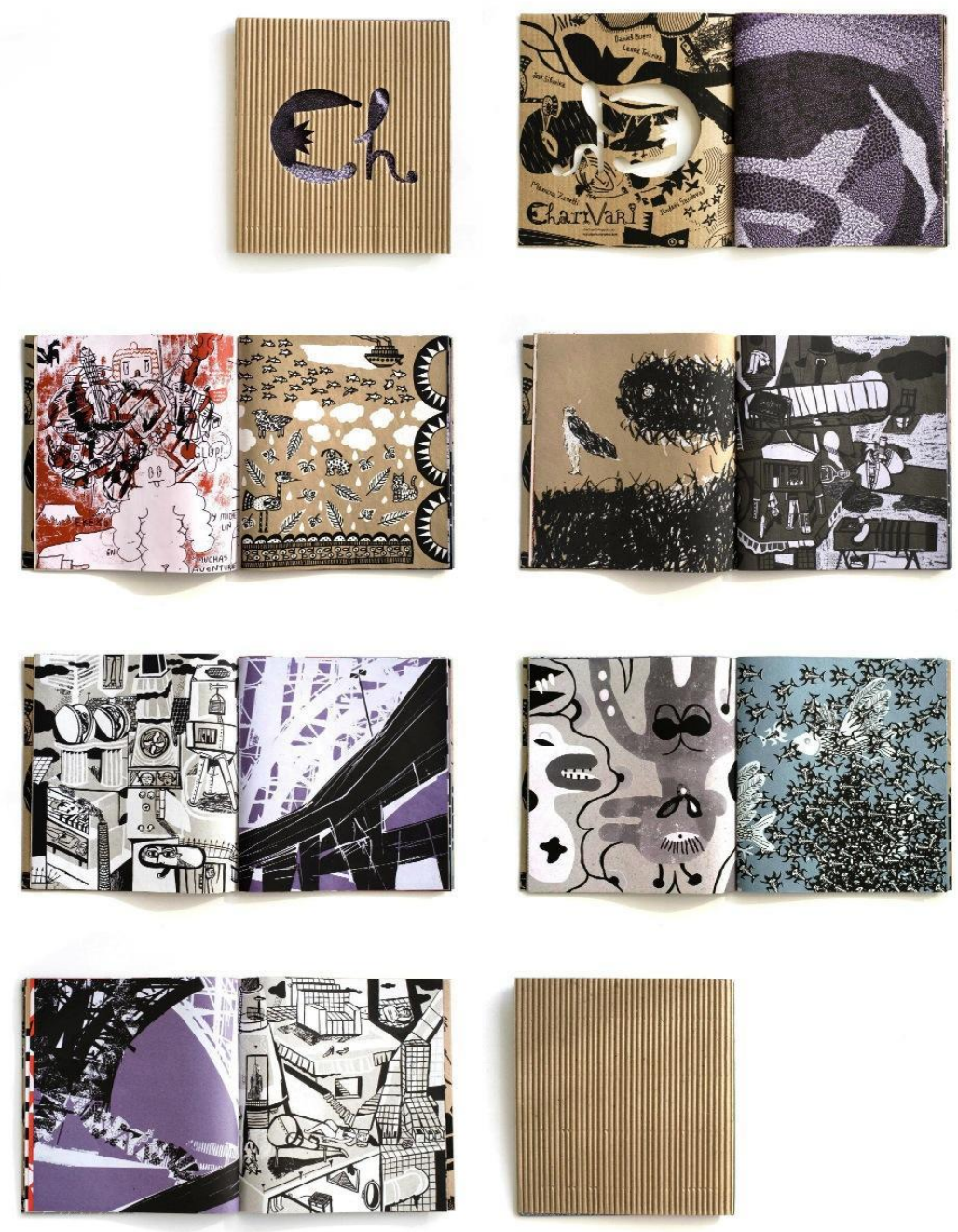

\section{Daniel Eizirik, João Kowacs, Denny Chang. Obra: Mineiros cavam no escuro.}

O livro "Mineiros cavam no escuro", 2015, mesmo com aparência convencional, dificilmente será encontrado em uma livraria tradicional. Tem tiragem de 800 exemplares e foi financiado pelo edital Pró-cultura do Rio Grande do Sul. Adquire-se apenas pelas mãos dos autores e em feiras de publicações independentes espalhadas pelo Brasil. Impresso em gráfica, costurado e com lombada quadrada, nada em seu aspecto físico nos faz crer que possa ser algo diferente de uma literatura comum.

O design da capa remete às estampas e tipografias de cadernos antigos, os chamados 'livroscaixa' que serviam para registros de contabilidade. Passa-se facilmente por um livro usado e gasto. Abaixo do título, o nome do autor fictício "D. D. Sanchez".

No mundo real, o autor da literatura do personagem Sanchez pai é o escritor João Kowacs, e as interferências do Sanchez filho foram desenvolvidas pelo idealizador do projeto, o artista Daniel Eizirik. A leitura completa da obra, mesmo que não linear, se dá graças ao design de uma terceira pessoa, Denny Chang. Todos eles porto-alegrenses. 
Figura 4: Capa e rosto de Mineiros cavam no escuro. Acervo do autor.

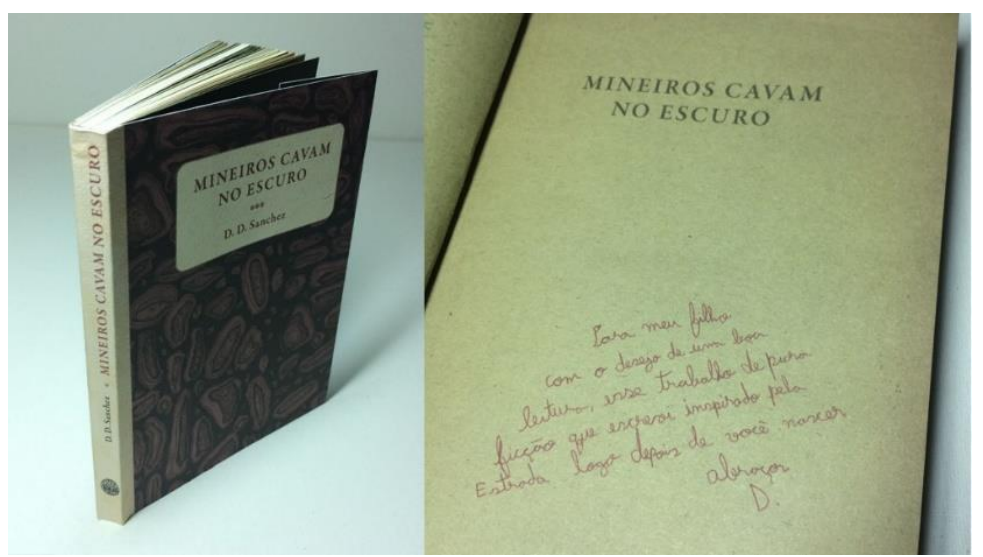

Figura 5: Índice e expediente fictícios, páginas internas. Acervo do autor.

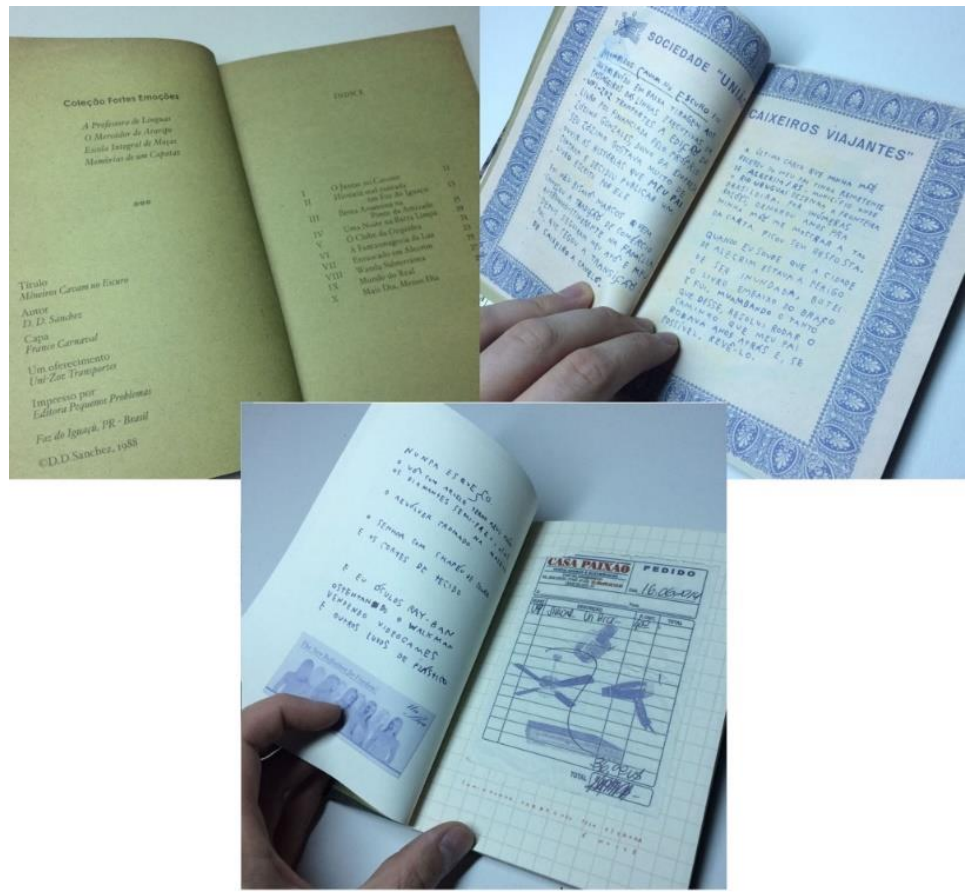

Figura 6: Páginas internas de Mineiros cavam no escuro. Acervo do autor.

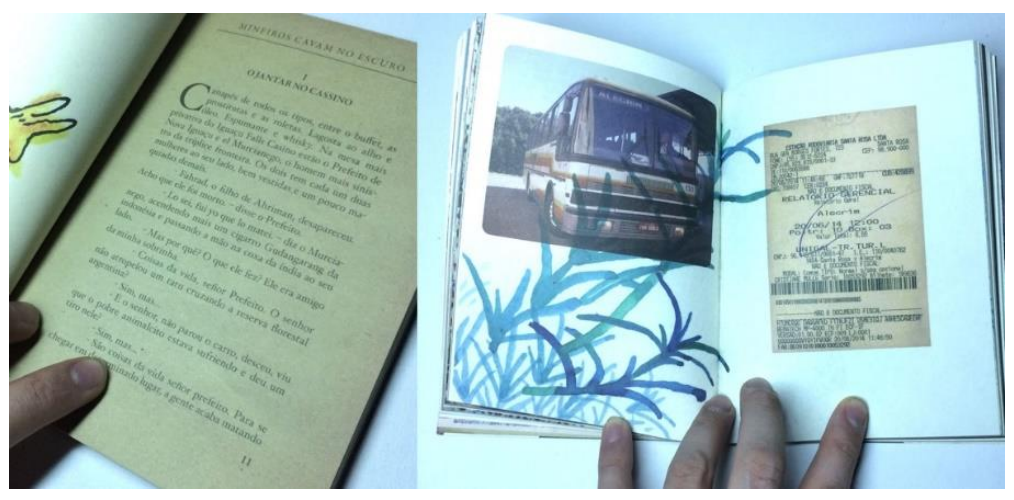

Anais do 9o Congresso Internacional de Design da Informação | CIDI 2019 
Desta forma, o livro é bem desenvolvido em uma autoria coletiva e ficcional, que intriga, instiga e confunde o leitor. Além disto, a narrativa quebrada se sabota atribuindo aos personagens as responsabilidades dos conteúdos e seus acidentes. Terminamos a obra acreditando na existência dos Sanchez. O pai, que teria escrito o texto principal, termina sua narrativa, mas não poderia imaginar que Sanchez filho faria interferências sobre seu livro impresso anos depois, com marcações, propagandas, recibos e guardanapos. O filho tampouco suspeitaria que nós, leitores de tudo isso, consumiríamos ambos os conteúdos em paralelo, gerando para nós uma nova conclusão. Trata-se de um efeito alcançado pelo conjunto de áreas de criação, alinhados na ação projetual, gerando uma poética que dificilmente seria atingida sozinho.

\section{Conclusões}

O desenvolvimento da pesquisa aponta que os objetos editoriais contemporâneos se distinguem por meio de projetos gráficos que contém elementos artesanais, experimentais e autorais. Remontam a práticas de grupos antigos, e desenvolvem-se hoje a partir de coletivos, transdisciplinaridade, coautoria ou autoria individual explorando novos papéis e atuações do designer enquanto autor (contexto, narrativas textuais e imagéticas), formador de opinião e produtor de cultura e do usuário e leitor como interator.

Assim, este tipo de objeto editorial é exemplo do desenvolvimento da produção cultural na nossa sociedade, reafirmando o design como uma manifestação cultural contemporânea. Não há como estudar o design - o editorial, em nosso recorte - desconectado do seu contexto histórico e social, pois a atividade cultural de cada tempo dialoga com o status daquela sociedade, e de certa forma, determina boa parte das características formais e simbólicas do material e objeto produzido.

A prática da auto publicação associada ao pensamento do design faz florescer a importante função social deste segmento. Com o acesso aos meios de produção facilitado, organização e projeto, vê-se uma movimentação em que pessoas que não tinham condição (financeira ou social) para produzir, agora se expressam por meio do objeto editorial de diversas maneiras.

O designer não é o único capaz, tampouco é superior a escritores, editores e artistas, mas é um profissional com vastos subsídios para assim atuar neste meio, se lhe convir, o que coincide com a percepção de protagonismo do design enquanto forte articulador na atual cena de feiras de publicações independentes, bem como da confecção de objetos editoriais contemporâneos.

\section{Referências}

Agamben, G. (2009) O que é o contemporâneo? Santa Catarina: Editora Argos.

Barthes, R. (2004) O rumor da língua. São Paulo: Martins Fontes,

Benjamin, W. (1994) O Narrador. Em Magia e técnica, arte e política: ensaios sobre literatura e história da cultura. São Paulo: Brasiliense.

Bomfim, G. A. (1997). Fundamentos de uma teoria transdisciplinar do design: morfologia dos objetos de uso e sistemas de comunicação. Em Estudos em Design, 5(2), pp. 27-41. Rio de Janeiro: AEND.

Burdek, B. E. (2010). Design: história, teoria e prática do design de produtos. São Paulo: Editora Blucher.

Coletivo Charivari. (2008). Charivari №2, São Paulo: publicação independente.

Eizirik, D., \& Kowacs, J. (2015). Mineiros não cavam no escuro: notas sobre a muamba. Porto Alegre: Independente.

Escorel, A. L. (2000). O efeito multiplicador do design. São Paulo: Senac. 
Featherstone, M. (1995). Cultura de consumo e pós-modernismo. São Paulo: Studio Nobel.

Krippendorf, K. (2001). Design centrado no ser humano. Em Estudos em Design, 8(3), pp. 8798, Rio de Janeiro: AEND.

Lima, G. C. (2014). O Gráfico Amador: as origens da moderna tipografia brasileira. $2^{\mathrm{a}}$ ed. Rio de Janeiro: Editora Verso Brasil.

Lipovetsky, G., \& Serroy, J. (2015). A estetização do mundo: viver na era do capitalismo artista. $1^{\underline{a}}$ ed. São Paulo: Companhia das Letras.

Lobach, B. (2001). Design Industrial. São Paulo: Blucher.

Lupton, E. \& miller, A. (Orgs.) (2008). ABC da Bauhaus. São Paulo: Cosac Naify.

Lupton, E. \& miller, A. (2011). Design, Escrita, Pesquisa: A escrita no design gráfico. Porto Alegre: Bookman.

Moles, A. A. (1981). Teoria dos Objetos. Rio de Janeiro: Tempo Brasileiro.

Moura, M. (2004). Design de hipermídia: relações entre cultura, linguagem, transdisciplinaridade e informação. Anais do I Congresso Internacional de Design da Informação. Recife: UFPE.

Moura, M. (2010). Poéticas do design contemporâneo: a reinvenção do objeto. Anais do III Seminário Nacional de Pesquisa em Cultura Visual. Goiânia: Editora da UFG.

Moura, M. (Org.). (2014). Design brasileiro contemporâneo: reflexões. São Paulo: Estação das Letras e Cores.

Moura, M. (Org.) (2015). Design contemporâneo: poéticas da diversidade no cotidiano. Em Fiorin, E.; Landim, P. C. \& Leonte, R. S. (Orgs.) Arte-ciência: processos criativos, pp. 61-80. São Paulo: Cultura Acadêmica.

Moura, M. (2016) Design e arte no contemporâneo: sentidos, estéticas e poéticas. Em CUNHA,

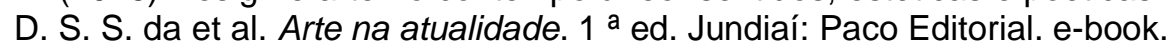

Muniz, J. de S., Jr. (2016). Girafas e bonsais: 'Independentes' na Argentina e no Brasil (1991 2015). Tese (Doutorado em Sociologia). São Paulo: FFLC-USP.

Muniz, J. de S., Jr. (2017). É dia de feira: a cena dos micro editores na cidade de São Paulo. Em 40ํㅡㄹ Congresso brasileiro de Ciências da Comunicação. Curitiba: Intercon.

Paiva, A. P. M. de. (2010). A aventura do livro experimental. São Paulo: Autêntica/EDUSP.

Piqueira, G. (2017). Oito viagens ao Brasil. São Paulo: WMF Martins Fontes/Independente.

Poynor, R. (2010). Abaixo às regras: design gráfico e pós-modernismo. São Paulo: Bookman.

Silveira, P. (2008). A página violada: da ternura à injúria na construção do livro de artista. $2^{\mathrm{a}}$ ed. Porto Alegre: UFRGS.

\section{Sobre os autores}

Jorge Otávio Zugliani, Mestrando, FAAC-UNESP-Universidade Estadual Paulista, Brasil <jozz@jozz.com.br>

Mônica Cristina de Moura, Doutora, FAAC-UNESP-Universidade Estadual Paulista, Brasil <monica.moura@unesp.br> 